УДК 81.42

ББК 81

DOI: https://doi.org/10.17308/lic.2020.3/2929

\title{
ПЕЙЗАЖНАЯ ЕДИНИЦА ХУДОЖЕСТВЕННОГО ТЕКСТА: СОВРЕМЕННЫЕ ПОДХОДЫ И ПЕРСПЕКТИВЫ ИССЛЕДОВАНИЯ
}

\author{
Л. В. Лаенко, А. М. Душкова \\ Воронежский государственный университет

\begin{abstract}
SCENERY UNIT OF LITERARY TEXT:
\end{abstract} \\ MODERN APPROACHES AND RESEARCH PERSPECTIVES
}

\author{
L. V. Laenko, A. M. Dushkova \\ Voronezh State University
}

\begin{abstract}
Аннотация: статья посвящена анализу современных подходов к изучению пейзажной единицы как компонента художественного текста с иелью определения ее сущчности на фоне других типов дескриптивных единии (портрета и интерьера) и степени ее изученности в лингвистике. Методом аналитического обзора исследований, объектом которых является такой дескриптивный компонент, выделяется ряд актуальных подходов к его рассмотрению (системно-структурный, типологический, функииональный, лингвокультурологический, лингвокогнитивный, лингвистика текста, теория информации), рассматриваются известные типологии пейзажной единиць, характеризуются их классификационные типь (семантический тип и его разновидности, грамматический тип и его разновидности, функциональный тип и его разновидности), утверждается, в том числе, функииональная нагруженность многочисленных выразительных средств языка в отмеченном типе дескриптивного фрагмента как для реализации авторского замысла, так и для его восприятия читателем. Делается вывод о значимости лингвокогнитивного подхода к анализу пейзажной единииьл, с позиций которого предлагается рассматривать такой фрагмент как обладающий фреймовой организацией его содержания, иентральным компонентом которого является концептуальная метафора.

Ключевые слова: пейзажная единица, художественный текст, научные подходы, типология, концептуальная метафора.
\end{abstract}

\begin{abstract}
: the article is devoted to the analysis of modern approaches to scenery unit study as a component of literary text in order to determine its essence in the context of other types of descriptive units (portrait and interior) and the degree of its study in linguistics. By the method of analytical review of works, investigating scenery unit, a number of relevant approaches to the consideration of such a component are distinguished (system and structural, typological, functional, linguocultural, linguocognitive, text linguistics, information theory). Furthermore, known typologies of such a unit are considered as well as their classification types are characterized (semantic type and its varieties, grammatical type and its varieties, functional type and its varieties). Besides, functional loading of numerous expressive language means in the noted type of descriptive fragment both for the realization of the author's message and for its perception by the reader is stated. As a result, significance of linguocognitive approach to scenery unit analysis is emphasized due to which the revealed frame organization of its content, the central component of which is conceptual metaphor, can be proved.
\end{abstract}

Key words: scenery unit, literary text, scientific approaches, typology, conceptual metaphor.

\section{Введение: постановка проблемы}

Актуальность проблематики настоящей статьи определяется, во-первых, тем, что художественный

(C) Лаенко Л. В., Душкова А. М., 2020 текст (далее - ХT) как объект научных изысканий непрестанно привлекает исследовательское внимание филологов (И. Р. Гальперин, Ю. И. Левин, В. Е. Хализев и др.), литературоведов (Ю. М. Лотман, Р. Барт,

Контент доступен под лицензией Creative Commons Attribution 4.0 License.

The content is available under Creative Commons Attribution 4.0 License. 
Ю. Н. Тынянов, М. М. Бахтин и др.), лингвистов (Н. Д. Арутюнова, Л. Г. Бабина, Л. М. Кольцова, Л. А. Новиков, Л. О. Чернейко и др.) в силу своей структуральной поликомпонентности, авторской тематической и мотивационной уникальности, креативной концептуальной содержательности, во-вторых, необходимостью лингвистического анализа проявляющихся новых аспектов такого типа объекта на фоне уже исследованных.

Так, благодаря исследованиям отмеченных и других ученых, получены ценные сведения о сущности XT, механизмах, факторах и условиях порождения такого типа текста, принципах, стратегиях и средствах воплощения авторского замысла в нем, единицах его структуры и смыслового содержания.

С позиций различных научных подходов разработан действенный категориальный аппарат относительно определения содержания понятия «художественный текст», которое сложно структурировано и полиаспектно, однако суммарно способное быть представленным на основе авторитетных представлений о нем, особенно же значимыми для нашего исследования являются следующие.

Текст художественного произведения может быть определен, вслед за Р. Бартом, как «пространство, где идет процесс образования значений, т. е. процесс означивания» [1, с. 414]. Автор вывел парадоксальную, на первый взгляд, оппозицию «произведение» - «текст», аргументировав свой взгляд тем, что «произведение наглядно, зримо, а текст - доказывается», «текст существует только в дискурсе», «текст не может неподвижно застыть, он по природе своей должен сквозь что-то двигаться» [1, с. 424].

Та же оппозиция дала возможность Ю. М. Лотману определить ХТ как один из уровней структуры произведения, «как один из элементов отношения», выявляющихся на фоне его «внетекстовых» элементов - «действительности, литературных норм, традиции, представлений» [2, с. 211].

Л. О. Чернейко отмечает, что ХT, как и любой текст, обладает внешней связностью, внутренней осмысленностью, возможностью своевременного восприятия. По мнению автора, «ХТ обладает и некоторыми отличительными чертами: эмоциональным воздействием на читателя и автореферентностью» [3, c. 112], уточняя, что «художественный текст располагает особыми средствами для создания впечатления реальности, жизненности описываемых событий. В художественном произведении событие не отражается, а преображается, проходя через сознание автора» [4, с. 442 и сл.].

В плане уточнения понятия художественного пространства и времени, в том числе и их корреляции, особую значимость представляют идеи Ю. М. Лотмана относительно ХТ и художественного простран- ства в нем, которое автор определяет как «модель мира данного автора, выраженную на языке его пространственных представлений» [5, с. 252 и сл.].

Действительно, пространство (и все его предметы) воспринимаемо, а время понимаемо. Изобразить пространство в художественном произведении можно, описав вещи, предметы, субстанцию. Как полагает Л. Е. Чернейко, «единственный способ изобразить время - показать движение либо вещей, либо взгляда. Движение взгляда и выполняет функцию изображения времени. В художественном тексте время и пространство могут быть разорваны. И разрывает их взгляд наблюдателя. Он же их и объединяет как самостоятельные единицы» [6, с. 66].

К настоящему времени аргументировано явление художественной картины мира [7-10], определено многоаспектное содержание такого понятия, сущность которого заключается в том, что «художественная картина мира - это скорее продукт перцепции, т. е. восприятие “со стороны"» [10]. Художественная картина мира включает в себя, помимо национальной картины (на которой основана индивидуально-авторская картина мира писателя) и непосредственно авторской позиции (т. е. собственно его индивидуального восприятия и толкования окружающей действительности), еще и индивидуальную картину мира читателя, так как художественная картина мира создается в сознании читателя под влиянием текста (произведения).

Представления об отмеченных аспектах осмысления ХТ как многогранного и уникального явления постоянно пересматриваются, уточняются и пополняются сообразно тем требованиям, которые предъявляются ему на каждом этапе развития науки о языке.

Так, весьма новым и ценным на наш взгляд, является выявление лингвистами определенных единиц XT дескриптивного характера, или дескриптивных фрагментов ХТ, под которыми понимаются художественные описания интерьера, портрета, пейзажа в том числе (далее - ПЕ) и которые получают в метаязыке современной лингвистики текста соответствующие определения, позиционирующие их авторское понимание.

\section{Типология дескриптивных фрагментов художественного текста}

Так, портрет в литературном произведении может быть определен как вид художественного описания, в котором изображается внешний облик персонажа с тех сторон, которые наиболее ярко представляют его в авторском видении. Портрет является одним из важнейших средств характеристики литературного героя [9, с. 218]. 
Отличие интерьера от пейзажа и портрета, как отмечает Л. Н. Дмитриевская, заключается лишь в объекте описания. Портрет, как отмечает автор, описывает внешний облик человека (создает образ героя); пейзаж описывает природу, т. е. создает ее образ, образ мира; интерьер, в свою очередь, описывает внутреннее пространство помещения и тем самым создает образ дома. Он играет важную роль в характеристике героя, создании атмосферы, необходимой для воплощения авторского замысла [11, с. 72].

Во многих литературоведческих и лингвистических работах именно пейзажу в художественных произведениях уделяется особое внимание. Наличие таких работ свидетельствует о ценности данного дескриптивного компонента художественного текста, перспективности его подробного и более глубокого изучения.

В общем понимании пейзажная единица как особый элемент текстовой структуры, имеющий свою семантику, в первую очередь, изобразительную, грамматическую выраженность средствами разных уровней языка (лексическим, синтаксическим, морфологическим), а также функциональную значимость для всего содержания текста, осмысляется авторами в конкретных метаопределениях по-разному, сообразно соответствующим научным подходам и парадигмам научного знания. Рассмотрим наиболее актуальные из них.

\section{Научные подходы к описанию пейзажной единицы художественного текста}

Системно-структурный подход. Согласно Г. И. Лушниковой, пейзажная лексика является ведущим участком в лексическом составе языка, наряду с лексикой антропологического характера. Автор анализирует лексические единицы, обозначающие элементы пейзажа в природе, в разных сферах употребления - научных и художественных текстах сравнительно с обиходной речью и тем самым отмечает, что, помимо первичных сем, служащих номинации элементов природы, в пейзажной лексике в поэзии и прозе могут реализовываться вторичные окказиональные, ассоциативные семы. «Благодаря этому, пейзажная лексика включается в тематическую сетку произведения и играет существенную роль в выражении его смысловой и эмоциональной образности» [12].

И. М. Вознесенская рассматривает лексико-семантические особенности пейзажных описаний русской природы, которые «являются проявлением присущей языку художественной литературы эстетической функции, выражающейся в особой системе отбора, сочетаемости и преобразования языковых единиц...» [13, с. 4]. Автор выявляет ключевые слова, анализирует их семантику, исследует особенности метафоры в описании природы, устанавливает семантические направления в развертывании художественно-образной конкретизации путем выявления лейтмотивного признака, который отражает особое состояние природы.

С. И. Болдырева [14], анализируя описания природы и внутреннее состояние персонажа в рамках заданного контекста, приходит к заключению, что образы природы нередко используются для выявления и мотивации эмоционального состояния персонажа. Исследуя семантику ведущих тематических слов поля «Природа» для выявления их потенциальных свойств - импликационного и эмоционального аспектов, автор прогнозирует параметры семантических приращений данных слов в стилистическом контексте и описывает механизм импликации в художественном произведении.

Лингвистика текста. Работа Ю. Ю. Худяевой [15] выполнена в рамках исследований по лингвистике текста, где словесно-художественный пейзаж автор рассматривает как компонент целостного текста. Автор устанавливает степень обособленности пейзажного описания на основе анализа особенностей его когезии с другими речевыми отрезками (описанием, повествованием, рассуждением и диалогом) в структуре текста художественных произведений французских романтиков. В исследовании аргументируется немаловажная роль эволюции пейзажных описаний в тексте французского романа: пейзажные описания, по заключению автора, приобрели форму отдельного графически выделенного абзаца, состоят из двух и более взаимосвязанных предложений и связаны с другими речевыми отрезками при помощи таких способов связи, как лексический, грамматический, логический, ассоциативный и стилистический.

В рамках данного подхода Б. Галанов определяет пейзаж как «изображение картин природы, обозначающее время и место действия в произведениях, и создающее определенное настроение» [16, с. 185].

Типологический подход. При изучении ПЕ О. А. Нечаевой выдвигаются задачи в области изучения «синтаксического единства» и стилистических категорий на типологической основе. Автор рассматривает пейзаж как «структурно-смысловой описательный жанр», как разновидность функционального типа монологической речи «описание», и при этом указывает на то, что в художественной литературе могут использоваться описания с точки зрения эмоционально-оценочного отношения автора к изображаемому. Среди таких описаний исследователь выделяет: описание с элементами лексической экспрессии; описание с синтаксическими формами оценки; образное описание с признаками в форме языковых символов [17]. 
Теория информации. В. Н. Рябовой в понятие ПЕ вкладывается как традиционное значение («вид местности», «описание природы»), закрепленное в толковых словарях (С. И. Ожегов), так и не совсем стандартное понимание этой текстовой единицы: все, что связано с природой, что не создано человеком [18]. По мнению автора, информация, которая заложена в пейзажной единице текста, может быть выражена по-разному. Это могут быть необычные словосочетания, в которых слова приобретают иные значения и тем самым являются носителями новой информации. Расположение элементов предложения при более углубленном анализе с позиций теории информации также, по мнению автора, оказывается носителем некой дополнительной информации.

Функциональный подход. Л. В. Поповская выясняет, каким образом ПЕ могут участвовать в создании повествовательного текста художественного произведения. В художественных произведениях ПЕ могут изучаться в двух аспектах: с точки зрения семантических и формальных связей пейзажного описания с повествованием и со стороны семантики, и со стороны структуры самих пейзажных единиц. При выявлении особенностей семантического и формального соотношения повествования и пейзажного описания, т. е. при выяснении того, как ПЕ вплетаются в ткань произведения и как при этом служат его раскрытию и образованию текста в целом, становится очевидной текстообразующая роль пейзажных единиц. В силу этого, пейзажное описание как одна из композиционно-речевых форм художественных произведений представляет возможности для его анализа и на уровне микросистемы пейзажного описания, и на уровне макросистемы всего текста [19].

Лингвокультурологическое и лингвокогнитивное направления. С точки зрения лингвокультурологии и лингвистики А. С. Выродова исследует понятие «колоратив» как один из аспектов ПЕ на базе поэтического творчества С. А. Есенина и Н. М. Рубцова. Автор доказывает, что цвет и свет, как и другие лексико-грамматические группы слов в языке, обладают своим значением, функциями, символикой и этимологией. Категория цвета является одной из основополагающих категорий культуры, которая способна отразить мировоззрение, эмоциональное и психическое состояние человека, стать ключом к пониманию картины мира личности. В своем труде автор разграничивает понятия лексическое и семантическое значение. Лексическое значение - это условное, общепринятое значение слова (цвета). Семантическое же значение сугубо индивидуально. А поэтическое творчество - это самая субъективная форма словесного творчества, где лирический герой выражает уникальные, сиюминутные переживания, палитру чувств, непосредственность мышления.
Именно поэтому, по убеждению автора, один и тот же цвет в творчестве даже одного и того же автора может иметь разную интерпретацию [20].

Р. С. Луценко [21] также подчеркивает значимость в текстопостроении такого структурного элемента, как пейзаж, который раскрывает представление человека об окружающем мире и позволяет проследить индивидуально-авторское восприятие мира сквозь призму такого элемента. Проблема художественного отображения окружающего мира в тексте рассматривается автором в рамках современных лингвистических направлений: когнитивной лингвистики и лингвокультурологии. Автор исходит из положения о том, что базовой категорией является концепт, позволяющий раскрыть законы текстопостроения: каналы связи изображения пейзажа и чувств лирического героя. Согласно Р. С. Луценко, структура пейзажного концепта художественных англоязычных произведений XIX-XX вв. отличается сложностью и иерархичностью. Она обогащается за счет общенационального, личностного и сенсорного компонентов. Автором была выявлена основная концептуальная задача пейзажных описаний: выражение внутреннего мира (чувств героев), отражение противостояния проявлений человеческого духа. Пейзажный концепт раскрывается, по мнению автора, в антропоцентрической парадигме, так как природа находится в тесной связи с человеком через образ автора, а его чувство природы отражается в тексте и переходит на героев.

Лингвокогнитивный подход к анализу ПЕ представляется наиболее перспективным в силу действенной системы методов (фреймовый, концептуальный анализы) в том смысле, что их использование позволяет глубже проникнуть в художественную ткань фрагмента и реконструировать его концептуальную структуру.

В итоге видится возможным сформулировать следующее определение ПЕ. Это сложно структурированный полифункциональный дескриптивный фрагмент художественного текста, участвующий в создании его композиционной целостности, который описывает, в отличие от интерьера, незамкнутое пространство внешнего мира, создается определенной системой средств языка, приобретающими в данном контексте изобразительную семантику, выступает как форма присутствия автора и как один из способов воплощения его художественного замысла.

Ценно также и то, что в рамках того или иного подхода многие лингвисты создают типологии пейзажных единиц в художественном тексте (см. исследования М. Ф. Вазиной [22], О. Ю. Лысовой [23], Е. И. Себиной [24]), существенным результатом которых представляется выделение классификационных типов ПЕ. 


\section{Типология пейзажных единиц}

Так, в результате анализа структурно-семантической организации пейзажных фрагментов художественного текста выделяются следующие классификационные типы ПЕ, имеющие соответствующие языковые средства выражения [23].

\section{А. Семантический тип и его разновидности.}

Подтип I. Способ восприятия основной информации пейзажной единицы: а) динамический (выражены предложениями и конструкциями с глаголом действия); б) статический (выражены признаковыми предложениями и конструкциями (причастные и придаточные обороты).

Подтип II. Основные разновидности информации в системе языка и текста.

2.1. Событийная (сюжетная) направленность: а) сезонный (время года); б) локальный (вид местности); в) темпоральный (время суток); г) метеорологический (погода); д) смешанный (ситуационно присутствуют все или некоторые из перечисленных выше признаков).

2.2. Социальнная направленность (в соответствии со спецификой объектов описания): а) сельские пейзажи; б) городские пейзажи; в) степные пейзажи; г) смешанные и промежуточные (лес, станция, проселочная дорога и т. д.) пейзажи.

2.3. Психологическая ситуативность: а) пейзаж-настроение; б) пейзаж-переживание.

2.4. Философская направленность: а) пейзаж-рассуждение; б) пейзаж-морально-этический; в) нестандартные варианты пейзажных единиц.

\section{Б. Грамматический тип пейзажных единиц и} его разновидности.

Подтип I. Синтаксическое оформление пейзажных единиц: а) полные модели пейзажных единиц (предложение, ССЦ); б) неполные (грамматически свернутые) модели пейзажных единиц; в) по форме коммуникативного выражения (диалог, монолог).

Подтип II. Лексическая наполняемость пейзажных единиц: а) времена года (summer, winter, spring); б) время суток (late night, evening, midnight, sunrise); в) погода (frost, breeze, fog, wind); г) космизмы (the sun, the moon); д) воздушно-пространственная перспектива (sky, air, space, clouds, horizon); е) вода (river, coast, ocean, beach); ж) населенный пункт (village, square, in the country, downtown, cave); з) земля (wood, road, mountain, hill); и) животный мир (horse, dog); птицы: raven, nightingale; насекомые: ants; к) растительный мир (flowers, trees bushes); л) настроение (hapiness, joy, sadness).

В. Функциональный тип пейзажной единицы и его разновидности в тексте: пейзаж-экспозиция, пейзаж-концовка, пейзаж-лейтмотив и пейзаж сквозная деталь.

Каждый из представленных типов ПЕ заслуживает, на наш взгляд, исследовательского внимания с учетом: 1) целей, художественных задач автора произведения и его мотивационной базы; 2) с ориентацией на реконструкцию тех имплицитных смыслов, которые репрезентированы в их семантической организации.

\section{Заключение}

Исследователями отмечается, что ПЕ как один из типов дескриптивных фрагментов XТ характеризуются использованием многочисленных выразительных средств языка (М. М. Асаева [25]; Я. А. Стефанишина [26]; Л. И. Тимофеева [27]): эпитет, сравнение, олицетворение, метонимия, гипербола, в том числе и метафора.

Языковая метафора по праву является одним из самых ярких и сильных средств создания выразительности и образности текста. Через метафорическое значение слов и словосочетаний автор текста, в первую очередь, усиливает зримость и наглядность изображаемого, а также передает неповторимость, индивидуальность предметов и явлений, проявляя при этом глубину видения мира. В художественном языке языковая метафора - это явление образного мышления, так как возбуждает и обогащает воображение, предоставляет восприятию эмоциональную окраску [28, с. 268].

За пределами исследовательского внимания уважаемых авторов, однако, остается изучение концептуальной метафоры в пространстве ПЕ художественного текста, сущность которой как базового когнитивного механизма заключается в переносе структуры одной понятийной области - источника - на другую - область цели. В результате такого переноса создается новое ментальное образование, которое и является концептуальной метафорой. В художественном тексте концептуальная метафора может быть репрезентирована различными языковыми средствами. Исходя из того, что, на наш взгляд, ПЕ как один из значимых концептов пространства ХТ, в том числе и англоязычного, имеет фреймовую структуру, состоящую из определенного набора элементов (субъект зрительного восприятия - пространство пейзажной сцены - объект/ объекты), которая требует специального анализа, полагаем актуальным, ценным и перспективным выявление и описание ментальных операций генерирования концептуальных метафор в отмеченном типе дескриптивного фрагмента, создание их классификации с последующим определением художественного и функционального потенциала каждого из их типов. 


\section{ЛИТЕРАТУРА}

1. Барт Р. Избранные работы : Семиотика. Поэтика. М. : Прогресс, 1994. 616 с.

2. Лотман Ю. М. Семиотика культуры и понятие текста // Русская словесность : от теории словесности к структуре текста. М. : Academia, 1997. С. 202-212.

3. Чернейко Л. О. Грамматика семантики // Памяти Анатолия Анатольевича Поликарпова : сб. науч. ст. М. : МГУ, 2015. С. 551-556.

4. Чернейко Л. О. Гипертекст как лингвистическая модель художественного текста // Структура и семантика художественного текста : докл. VII Междунар. конф. M., 1999. C. 439-460.

5. Лотман Ю. М. Текст как динамическая система // Структура текста-81 : тез. симпозиума. М. : ИСл РАН, 1981. C. 104-105.

6. Чернейко Л. О. Как рождается смысл. Смысловая структура художественного текста и лингвистические принципы ее моделирования : учеб. пособие по спецкурсу для студентов. М. : Гнозис, 2017. 208 с.

7. Чарыкова О. Н. Роль глагола в репрезентации индивидуально-авторской модели мира в художественном тексте : автореф. дис. ... канд. филол. наук. Воронеж, 2000. 23 c.

8. Мейлах Б. С. Художественная картина мира как комплексная проблема // Процесс творчества и художественное восприятие : комплексный подход : опыт, поиски, перспективы. М. : Искусство, 1985. 318 с.

9. Хализев B. E. Теория литературы : учебник. М. : Высшая школа, 2002. 437 с.

10. Фещенко О. А. Концепт ДОМ в художественной картине мира М. И. Цветаевой (на материале прозаических произведений) : автореф. дис. ... канд. филол. наук. Новосибирск, 2005. 23 с.

11. Дмитриевская Л. Н. Интерьер в литературе (на примере романа Е. Замятина «Мы» // Ежегод. сб. науч.-метод. материалов. М. : МГОУ, 2010. № 3. С. 72-84.

12. Лушникова Г. И. Пейзажная лексика современного английского языка в терминологии и поэзии : автореф. дис. ... канд. филол. наук. Кемерово, 1986. 16 с.

13. Вознесенская И. М. Лексика поэтических описаний русской природы : автореф. дис. ... канд. филол. наук. Ленинград, 1984. 17 с.

14. Болдырева С. И. Двухфокусный образный контекст в английской художественной прозе : автореф. дис. ... д-ра филол. наук. Ленинград, 1989. 24 с.

15. Худяева Ю. Ю. Различие в степени когезии отдельных элементов в общей структуре текста : автореф. дис. ... канд. филол. наук. СПб., 2001. 23 с.

16. Галанов Б. Е. Живопись словом. Портрет. Пейзаж. Вещь. М. : Советский писатель, 1974. 343 с.

17. Нечаева $O$. A. Типы речи и работа над ними в школе : учеб. пособие. Красноярск, 1989. 166 с.

18. Рябова В. Н. Пейзажная единица текста : семантика, грамматическая форма, функция (на материале произведений А. П. Чехова) : автореф. дис. ... канд. филол. наук. Тамбов, 2002. 25 с.
19. Поповская (Лисиченко) Л. В. Лингвистический анализ художественного текста в вузе : учеб. пособие для студ. филол. факультетов. 2-е изд., доп. и перераб. Ростов н/Д. : Феникс, 2006. 512 с.

20. Выродова А. С. Лингвокультурологическое пространство колоративов в русском поэтическом дискурсе первой половины XX века : на материале поэтических текстов С. А. Есенина и Н. М. Рубцова : автореф. дис. ... канд. филол. наук. Белгород, 2008. 22 с.

21. Луиеенко P. С. Концепт «пейзаж» в структуре англоязычного прозаического текста : автореф. дис. ... канд. филол. наук. Саранск, 2007. 23 с.

22. Вазина М. Ф. Природа в прозе И. А. Бунина : автореф. дис. ... канд. филол. наук. СПб., 2000. 19 с.

23. Лысова О. О. Структурно-семантическая организация описательных фрагментов текста : автореф. дис. ... канд. филол. наук. Уфа, 1998. 21 с.

24. Себина Е. И. Пейзаж // Введение в литературоведение. Литературное произведение : основные понятия и термины : учеб. пособие. М. : Академия, 2000. С. $228-240$.

25. Асаева М. М. Речевые средства выразительности в автобиографической прозе О. Э. Мандельштама : автореф. дис. ... канд. филол. наук. Махачкала, 2009. 23 с.

26. Стефанишина Я. А. Стилистические выразительные средства в романе Дж. Голсуорси «Собственник» и их перевод на русский язык : автореф. дис. ... канд. филол. наук. М., 2005. 28 с.

27. Тимофеева О. В. Метафора в художественной репрезентации мира (на материале произведений английских и американских писателей) : автореф. дис. ... канд. филол. наук. М., 2011. 23 с.

28. Хазагеров Т. Г. Экспрессивная стилистика и методика анализа художественных текстов // Проблемы экспрессивной стилистики / под ред. Т. Г. Хазагерова. Ростов на/Д., 1992. Вып. 2. С. 47-55.

\section{REFERENCES}

1. Bart R. Izbrannye raboty: Semiotika. Poehtika [Selected works: Semiotics. Poetics]. Moscow: Progress, 1994. $616 \mathrm{p}$.

2. Lotman Y. M. Semiotika kultury i ponyatie teksta [Semiotics of culture and concept of text ]. In Russkaya slovesnost': Ot teorii slovesnosti k strukture teksta. Moscow: Academia, 1997. Pp. 202-212.

3. Chernejko L. O. Grammatika semantiki [Grammar of Semantics]. In Pamyati Anatoliya Anatol'evicha Polikarpova. Sbornik nauch. statej. Moscow: Moscow State University, 2015. Pp. 551-556.

4. Chernejko L. O. Gipertekst kak lingvisticheskaya model' khudozhestvennogo teksta [Hypertext as a linguistic model of artistic text]. In Struktura i semantika khudozhestvennogo teksta: Doklady VII Mezhdunarodnoj konferentsii. Moscow: 1999. Pp. 439-460.

5. Lotman Y. M. Tekst kak dinamicheskaya sistema [Text as a dynamic system]. In Struktura teksta-81: tezisy simpoziuma. Moscow: ISl RAN, 1981. Pp. 104-105. 
6. Chernejko L. O. Kak rozhdaetsya smysl. Smyslovaya struktura khudozhestvennogo teksta i lingvisticheskie printsipy ee modelirovaniya: uchebnoe posobie po spetskursu dlya studentov [How a sense is born. Semantic structure of artistic text and linguistic principles of its modeling: tutorial on special course for students]. Moscow: Gnozis, 2017. $208 \mathrm{p}$.

7. Charykova O. N. Rol' glagola v reprezentatsii individual'no-avtorskoj modeli mira $\mathrm{v}$ khudozhestvennom tekste. [The role of the verb in the representation of the individual model of the world in the artistic text]. PhD Dissertation Abstract. Voronezh: Voronezh State University, 2000. 23 p

8. Mejlakh B. S. Khudozhestvennaya kartina mira kak kompleksnaya problema [An artistic picture of the world as a complex problem]. In Protsess tvorchestva i khudozhestvennoe vospriyatie: Kompleksnyj podkhod: opyt, poiski, perspektivy. Moscow: Iskusstvo, 1985. 318 p.

9. Khalizev V. E. Teoriya literatury [Theory of literature]. Moscow: Vysshaya shkola, 2002. 437 p.

10. Feshhenko O. A. Kontsept DOMv khudozhestvennoj kartine mira M. I. Tsvetaevoj (na materiale prozaicheskikh proizvedenij) [Concept HOUSE in the world art painting of M. I. Tsvetayeva (on the material of prosaic works)] PhD Dissertation Abstract. Novosibirsk: Novosibirsk State University, 2005. 23 p.

11. Dmitrievskaya L. N. Inter'er v literature (na primere romana E. Zamyatina «My» [Interior in literature (based on E. Zamyatin's novel "We"]: Ezhegodnyj sbornik nauchno-metodicheskih materialov. Moscow: MGOU, 2010. No. 3. Pp. 72-84.

12. Lushnikova G. I. Pejzazhnaya leksika sovremennogo anglijskogo yazyka $v$ terminologii i poehzii [Landscape vocabulary of modern English in terminology and poetry]. PhD Dissertation Abstract. Kemerovo: Kemerovo State University, 1986. $16 \mathrm{p}$.

13. Voznesenskaya I. M. Leksika poehticheskikh opisanij russkoj prirody [Vocabulary of poetic descriptions of Russian nature]. PhD Dissertation Abstract. Leningrad: Leningrad State Univesity named after A. A. Zhdanov, 1984. $17 \mathrm{p}$.

14. Boldyreva S. I. Dvukhfokusnyj obraznyj kontekst v anglijskoj khudozhestvennoj proze [Two-focus figurative context in English art prose]. PhD Dissertation Abstract. Leningrad: Leningrad State University named after A. A. Zhdanov, 1989. 24 p.

15. Khudyaeva Y. Y. Razlichie v stepeni kogezii otdel'nykh ehlementov $v$ obshhej strukture teksta [Difference in the degree of cohesion of individual elements in the overall structure of the text]. PhD Dissertation Abstract. St.Petersburg: RGPU named after A. I. Gertsen, 2001. 23 p.

16. Galanov B. E. Zhivopis'slovom. Portret. Pejzazh. Vesh' ' [Painting by a word. Portrait. Landscape. Thing.]. Moscow: Sovetskij pisatel', 1974. 343 p.

17. Nechaeva O. A. Tipy rechi i rabota nad nimi v shkole [Speech types and working on them in school]. Krasnoyarsk: 1989. 166 p.
18. Ryabova V. N. Pejzazhnaya edinitsa teksta: semantika, grammaticheskaya forma, funktsiya (na materiale proizvedenij A. P. Chekhova) [Landscape unit of text: semantics, grammatical form, function (based on A. P. Chekhov's works)]. PhD Dissertation Abstract. Tambov: Tambov State University, 2002. 25 p.

19. Popovskaya (Lisichenko) L.V. Lingvisticheskij analiz khudozhestvennogo teksta $v$ vuze [Linguistic analysis of artistic text in the university]. 2nd Edition. Rostov-onDon: Feniks, 2006. 512 p.

20. Vyrodova A. S. Lingvokul turologicheskoe prostranstvo kolorativov v russkom poehticheskom diskurse pervoj poloviny XX veka: na materiale poehticheskikh tekstov S. A. Esenina i N. M. Rubtsova [Linguoculturological space of coloratives in the Russian poetry discourse of the first half of the 20th century: based on S. A. Esenin and N. M. Rubtsov's poetry]. PhD Dissertation Abstract. Belgorod: Belgorod State University, 2008. 22 p.

21. Lutsenko R. S. Kontsept «pejzazh»v strukture angloyazychnogo prozaicheskogo teksta [Concept of "landscape" in the structure of English-language prosaic text]. PhD Dissertation Abstract. Saransk: Saransk State University, 2007. $23 \mathrm{p}$.

22. Vazina M. F. Priroda v proze I. A. Bunina [Nature in I. A. Bunin's prose]. PhD Dissertation Abstract. Saint-Petersburg: Saint-Petersburg State University, 2000. 19 p.

23. Lysova O. YU. Strukturno-semanticheskaya organizatsiya opisatel'nykh fragmentov teksta [Structural and semantic organization of descriptive text fragments]. PhD Dissertation Abstract. Ufa: Samara State University, 1998. $21 \mathrm{p}$.

24. Sebina E. I. Pejzazh [Landscape]. In Vvedenie v literaturovedenie. Literaturnoe proizvedenie: Osnovnye ponyatiya i terminy. Moscow: Akademiya, 2000. Pp. 228240.

25. Asaeva M. M. Rechevye sredstva vyrazitel'nostiv avtobiograficheskoj proze O. E. Mandel'shtama [Speech means of expressiveness in O. E. Mandelstam's autobiographical prose]. PhD Dissertation Abstract. Makhachkala: Dagestan State University, 2009. 23 p.

26. Stefanishina Y. A. Stilisticheskie vyrazitel'nye sredstva v romane Dzh. Golsuorsi "Sobstvennik" $i$ ikh perevod na russkij yazyk [Stylistic expressive means in J. Golsuorsi "s novel "The Owner" and their translation into Russian]. PhD Dissertation Abstract. Moscow: Moscow State Regional University, 2005. 28 p.

27. Timofeeva O. V. Metafora v khudozhestvennoj reprezentatsii mira (na materiale proizvedenij anglijskikh $i$ amerikanskikh pisatelej) [Metaphor in the artistic representation of the world (based on English and American writers' works]. PhD Dissertation Abstract. Moscow: Moscow State Regional University, 2011. 23 p.

28. Khazagerov T. G. Ehkspressivnaya stilistika i metodika analiza khudozhestvennykh tekstov [Expressive stylistics and techniques for analyzing artistic texts]. In Problemy ehkspressivnoj stilistiki. Ed. by T. G. Khazagerov. Issue 2. Rostov-on-Don: RGU, 1992. Pp. 47-55. 
Воронежский государственный университет Лаенко Л. В., доктор филологических наук, профессор кафедры английской филологии

E-mail: lvlaenko@mail.ru

Душкова А. М., аспирант кафедры английской филологии

E-mail: dushkova.aleksandra@mail.ru

Поступила в редакичию 27 марта 2020 г.

Принята к публикаџии 15 июня 2020 г.

\section{Для цичтирования:}

Лаенко Л. В., Душкова А. М. Пейзажная единица художественного текста: современные подходы и перспективы исследования // Вестник Воронежского государственного университета. Серия: Лингвистика и межкультурная коммуникация. 2020. № 3. C. 34-41. DOI: https://doi.org/10.17308/lic.2020.3/2929
Voronezh State University

Laenko L. V., Doctor of Philology, Professor of the English Philology Department

E-mail:Lvlaenko@mail.ru

Dushkova A. M., Post-graduate Student of the English Philology Department

E-mail:dushkova.aleksandra@mail.ru

Received: 27 March 2020

Accepted: 15 June 2020

\section{For citation:}

Laenko L. V., Dushkova A. M. Scenery unit of literary text: modern approaches and research perspectives. Proceedings of Voronezh State University. Series: Linguistics and Intercultural Communication. 2020. No. 3. Pp. 34-41. DOI: https://doi.org/10.17308/lic.2020.3/2929 